\title{
What Makes a Surgical Teacher Great?
}

\section{Dhananjaya Sharma ${ }^{1} \cdot$ Sandeep Kumar ${ }^{2}$}

Accepted: 13 October 2020 / Published online: 21 October 2020

(C) Association of Surgeons of India 2020

A great surgical teacher is revered, but "what makes a surgical teacher great?" is not so easy to define. Teaching is a soft skill, and there are no many objective scales to assess teaching abilities. A recent systemic review found only 23 studies on this crucial topic; all of these touched upon global qualities of a good teacher. Of these, three-fourth studies did not define the qualities of a great surgical teacher [1]. Another review mentioned 4 important themes as positive attributes of great surgical teacher: "character" (approachability, patience, enthusiasm, encouraging/supportiveness), "procedural" (willingness to let trainee operate, balance between supervision and independence), "teamwork and communication" (sets educational aims and objectives, ability to use appropriate feedback, communication skills, and time availability to train), and "clinical" (capable, good relationships with patients, and the healthcare team) [2]. All of us know that above everything else, great surgical teachers are first and foremost good doctors who provide exceptional patient care which goes hand-inhand with effective surgical teaching and forms its foundation $[3,4]$.

Fame of great surgical teachers is not confined to their hospitals, but it spreads all over the world as their disciples carry it with them. "Swadeshe pujyate raja, vidwan sarvatra pujyate - The emperor is worshiped in the territory of his kingdom but the scholars are bestowed respect all over the world."

Much before the calamity and distress of COVID pandemic, surgical teaching was already facing multidimensional challenges and proved demanding to teach the rapidly evolving surgical technologies. Increasing time constraints due to

Dhananjaya Sharma

dhanshar@gmail.com

Sandeep Kumar

profsandeepsurgeon@gmail.com

1 Department of Surgery, Government NSCB Medical College, Jabalpur, MP 482003, India

2 Indian Journal of Surgery, Lucknow 226024, India decreasing resident learning hours, lack of longitudinal relationships with residents due to their rotations, increasing patient demands, increasing emphasis on patient safety issues, and their audits and cost constraints due to healthcare economics and many other oddities made the problem worse. This pandemic has further compounded these challenges and caused a major disruption of surgical teaching. This calls for more efficient surgical teaching as the skill and the pride of future surgeons is at stakes.

\section{Global Teaching Skills}

Very few great surgical teachers have had formal teacher's training, but their instinct of conscientiousness paved their way to move forward. They demonstrate global teaching skills. They have mastery over basic teaching competencies like commitment to teaching, learner engagement, learnercenteredness, content knowledge, and relevance. Their clinical and operative competence, interpersonal and communication skills, professionalism and role modelling to set an example, deep empathy towards the patient and absolutely no greed automatically provide them an aura of a guru. In addition, curriculum design and implementation, evaluation and egalitarianism, and demonstration of leadership make them inspirational mentors. Most renowned global teachers are silvertongued orators and experts in the art and science of pedagogy $[5,6]$. They understood "andragogy" and quickly switched over to aspirational and "cognitive-based" learning approaches (learner-centric with trainees as active participants in all facets of learning) rather than opting for "behavioral" (teacher-centric, where trainees are passive responders). They quickly recognize the level of seniority and ability level of their audience $[4,7]$. The ultimate aim of all education is to achieve high quality of surgical practice in the community. Great teachers understood all three kinds of transfers to their trainees: from a priori knowledge to learning, from learning to new learning, and from learning to application via vertical transfer of knowledge - which is truly translational transition 
from teaching to practice. This leads them to objectively judge trainee's growth and gradually change them from an "instiller" to $a$ "facilitator." Many practice the art of Socratic teaching and encourage argumentative dialogue to stimulate critical thinking and gently nudge the trainee to the right answer.

\section{Clinical Teaching}

All surgeons have fond memories of their great clinical teachers and their memorable teaching moments. However, if asked to quantify the objective measurements of teaching skills and qualities, these are generally incomprehensible. It may be possible to name some of the qualities of their great clinical teachers. And generally, the students when describing their teachers as "great" recall them as: consummate clinicians with mastery in their respective subject, proficient in communication skills, clinical diagnostic reasoning, learner-centered teaching, organizational and planning skills (arranging suitable patients) that foster a collaborative learning climate; open and reflective for feedback and have plenty of time and enthusiasm for demonstrating and themselves demonstrate physical signs and clinical skills during bedside teachings and procedures $[8,9]$. They effortlessly demonstrate the scientific relevance of clinical findings by linking them to the basic sciences and simulate diagnostic clinical workup to bedside detective work thereby make learning fun. They would systematically discuss the algorithmic serial and parallel testing for diagnostic work up [10]. When faced with limited time, brief structured modules are successfully used by great teachers [11]. Such teachers have noncognitive qualities and personal attributes, such as relationship skills and personality type, that allows them to transcend the boundaries of ordinary teaching. They project an aura around them which is that what their trainees remember in every breath [12].

\section{Perioperative Teaching}

Operation rooms (ORs) were called "operating theatres," where the performances of surgery were witnessed by the general public. Operating table was a central "stage" where surgeons acted as thespians do. Each one of us have unforgettable memories of some of our surgical teachers' captivating escapades made the technique itself the great art of teaching. The difficult dissection done with aplomb with a snip of scissors or with electrosurgical cautery, the perfect anastomosis, the unflappable response when called to deal with an inadvertent hole in IVC and there goes the Satinsky clamp and the rent repaired by a 5-0 prolene; and the list goes on.......!
Teaching surgical steps or guiding surgical skill development and operating theatre behavior include a lot of selfdiscipline and complementing the operating trainee. Teaching during a major surgical procedure is determined by light or heavy case schedule, patient's permission, patient's morbidity, procedural level of technical difficulty, trainee's competence, and his trustworthiness. The previous experience of the mentee with various procedures also determines the independent operating work he/she can gradually take on. Assessment of trainees' mental readiness and operative competency determine the level of graded responsibility (opening/ closure/partial/full surgery) allotted to them. Meticulous surgical dissection without much blood loss is greatly appreciated. Undue time taken, prolonging anesthesia and blood loss and non-progressive surgery will prompt the teacher to wash up and join the operating team [13]. Great mentors instinctively know what the trainees want and employ many of the principles of learning theory [14]. They teach with enthusiasm and are passionate about it, excel at communication, demonstrate clinical and technical expertise and professionalism, ensure a structured per-operative teaching debrief, provide a "handson" learning experience, prevent errors by trainees and teach recovery strategies; have leadership and mentorship skills; and assure a positive learning climate by being kind and courteous; and providing timely constructive feedback $[1,7,15,16]$.

When the resident is operating, great teachers query the residents' knowledge about specific steps, augment verbal instruction (deconstruction of operative procedure like describing relevant anatomy, explaining the rationale behind a specific step, guiding the trainee to perform the next step, etc.) with small physical actions (supporting or retracting tissues, guiding/repositioning the trainee's hands/ instruments, etc.). They pause the surgical procedure to explain the larger picture, create memorable coined names, and issue highly specific commands resulting in prevention of surgical errors to achieve teaching and surgical goals simultaneously. These instructions may be laced with terse language, anecdotal colorful verbal analogies, and sometimes banter and humor [17-20]. Close interaction during trainee's operating stint has been called "intelligent cooperation" and allows the teacher in providing the critical scaffolding [21]. Some teachers have anecdotes for a particular situation in the operating room, and they would repeat these for subsequent batches and are remembered by generations of their trainees. They could create an imagery situation during their teaching session, crack the joke appropriately, and end with the definite and intelligible cue. These moments stick into the minds of the trainees. Even informal encounters with great surgical teachers are full of pearls of wisdom and memorable vignettes.

A recent systemic review evaluated 34 studies on intraoperative teaching with the help of Medical Education Research Study Quality Instrument (MERSQI) and concluded that structured interventions in the form of briefing, intraoperative 
teaching, and debriefing (BID) model were graded as most important and impactful [22].

\section{Do Residents and Teacher Assess the Efficacy of Teaching/Training Similarly?}

Many studies have addressed this important issue and most have found that in spite of common grounds, there is significant disagreement between residents and teaching faculty, especially in the operating room teaching which is fundamental to the development of a surgical resident [23]. The reasons for this are not different to understand as both want and expect different things from each other: residents want greater teaching stress on steps like "instrument use," "suture selection," and "operative field exposure," while faculty felt residents are not properly prepared with basics like "surgical anatomy," "natural history of disease," and "procedure choices." Teachers value and practice adult learning principles and expect better preparation and participation in the process of learning $[24,25]$.

The opinion on what attributes a good surgical teacher should possess varied between the trainees and teachers. Key attributes identified by teachers were giving feedback, setting targets for trainees, and inspiring trainees. While the trainees' list included leading them in difficult situations, patience, ensuring trainees perform cases, inspiring trainees, and being a role model. As expected, these views change with the level of trainees and teachers [26]. It seems that either the teachers overestimate the quality of teaching they provide or trainees fail to recognize the teaching which they receive [27].

\section{What Is the Importance of Feedback?}

Atmosphere for mentor-mentee feedback should be forged by traditions. There may be some disagreements between resident's and teachers' perception of efficacy of surgical teaching, and this makes healthy communication flow in the form of resident's structured feedback and meaningful analysis even more important for improvement in teaching [27, 28]. Teacher to trainee feedback is an important intervention and improves surgical skills of the trainee, reduces errors, and results in a smoother learning curve [29]. There is no doubt that every type of feedback - teacher to trainee and/or trainee to teacher-improves surgical teaching, but there is still need for improved quality and quantity of structured feedback. Great teachers define learning objectives in the beginning and at the end of the session take a feedback on how many of those objectives were achieved during the session.

\section{Are There Any Objective Criteria to Assess Quality of Surgical Training?}

A global Delphi consensus study on defining and measuring quality in surgical training found consensus on following themes for the Surgical Training Quality Assessment Tool (S-QAT): relationship between the trainer and trainee, operative exposure, supervision, trainee feedback, trainer feedback, structure and organization, structured teaching programs, and trainee improvement [30].

Most tools (SETQ, "System for Evaluation Teaching Qualities"; BIDAT, "Briefing-Intraoperative teachingDebriefing Assessment Tool"; STEEM, "Surgical theatre educational environment measure") assessing surgical teaching use Likert's scales for various teaching parameters like explaining orientation/objectives with the case, sustaining a positive learning atmosphere, sharing up-to-date knowledge of developments in the field, and encouraging questions, feedback, positive reinforcement, and active participation, while maintaining a climate of mutual respect for all trainees. Their assessment of operative room teaching include various teaching parameters like the teacher describing upcoming surgical procedure, operative approach, rationale, and alternatives; discussing expected patient outcomes and possible complications; clarifying resident roles and responsibilities; demonstrating technical skills with confidence and expertise; resident participation in procedures according to ability; demonstrating awareness and sensitivity to resident learning needs; answering questions clearly and precisely; stimulating the residents to think critically for problem solving; and providing direct and ongoing feedback regarding resident progress [31-34].

A review of available instruments for trainees' feedback evaluating clinical teachers found wide ranges in evaluators, evaluations, and measured items, and found validation of instruments comprised solely of interpersonal and clinicalteaching domains [35]. Unsurprisingly, trainees take in high esteem only those few teachers who had taken training for teaching and those who spend lots of time in teaching. Trainees' relationship with their supervisor correlated most strongly with overall satisfaction [36]. It may be "Hawthorne effect" but a deliberate focus on objectively assessing teaching surgeon's peri-operative teaching motivates them, improves teaching, and provides objective criteria for faculty evaluation so those who excel at surgical teaching can be rewarded [37, 38].

\section{Can Surgeons "Learn How to Teach" and Improve as Teachers?}

The answer is yes! Earlier, there was no formal training for surgical teachers; they were just experts in what they taught, but most of them learned the art and science of teaching as 
they went along by informal experiential learning [39]. Now, several universities and national organizations like Medical Council of India run short teaching-improvement workshops/courses which enable medical teachers to understand basic educational theories, knowledge gaps related to education, the role of teaching for surgeons, teaching tools to improve teaching performance, setting learning goals, curriculum development/evaluation, creating teaching content, assessment of learning, educational research, their own individual needs, and how to improve interactive experiences with learners [40]. The universities/teaching institutes and national societies can empower surgeons to excel as teachers by supporting educational leadership opportunities, support for medical education, opportunities and funding for medical education research, feedback from students and peers, faculty development and mentoring, and reward teaching by valuing it at par with patient care and investigative research and awarding recognition for teaching excellence [41, 42]. Such efforts help the surgeons in developing self-awareness as teachers and have been associated with positive outcomes [43].

\section{Surgical Teacher Has to Master Newer Technologies}

Ability to learn and master newer technology for patient care and teaching has been the hallmark of all great surgical teachers. They are giants who can straddle two different worlds and could make smooth transition from one to the next. Earlier, it was embracing the technology of minimally invasive surgery including robotics, and teaching finer nuances of science, technique, and emerging technology and developing appropriate curricula and assessment methods. The COVID pandemic has disrupted the conventional surgical teaching globally, but nimble footwork has ensured that great teachers have quickly risen to the challenge and adopted various virtual teaching models with great alacrity. Video conferencing, scheduled online classes/courses, webinars, e-simulations, and other remote teaching digital/e-models are being freely used with great felicity and have opened a new e-world for great teachers to share their wisdom even more easily with a wider audience across the globe.

\section{Surgical Teacher as an Apostle for Evidence Based Surgical Practice and Research}

The past 2 decades have witnessed increasing use of evidencebased practice, research and translational research to implement efficacious treatment studies. Great surgical teachers inadvertently ingrain this practice of not using bogus treatments and emphasize the levels of evidence on which their decisions are made. They are excellent proponents of research and always have a lingering idea to be pursued by a case control or an experimental model to test their hypothesis. They are not mundane, non-numerate, gray-haired surgical showmen but equally understand and appreciate the application of biostatistics. Whenever there is an enthusiastic resident keen to take up a research project or publish an article, great teachers are there as a ready-reckoner. They would never emphasize a treatment that they want to follow by revealing an anecdote but if they must pursue a treatment strategy which is contrary to the evidence prevailing at that time, they would have a justification. They understand what all has been shown as efficacious in a trial may not be as effective in the given situation. They may not practice cook-book medicine and have their own recipes. It requires a bottom-up approach that integrates the best external evidence with individual expertise, available resources, and patient's choice [44].

\section{So What Makes a Surgical Teacher Great?}

\author{
"Guru kumhar shishya kumbh hai; garhi garhi kade \\ khot, Antar haath sahar de; bahar bahar chot."
}

The analogy of a great surgical teacher is elucidated in the verse composed by fifteenth century mystic poet Kabir with a potter who brings out a perfect spherical mud - vessel on the moving plate out of a doughed-mud. This cast by the potter is shaped by the gentle patting of one palm on the outside of pot body while the other palm kept supporting the pot body inside.

It is a herculean academic exercise to actually fathom the in-depth virtues of a teacher - as teaching is an act which appears the part of the whole, but even if the part is taken out, the remainder is whole. The literature of our proud heritage "Sanskrit" does justice to humanity's adoration for the teacher with various titles viz., "Adhyapak," "Upadhyaya," "Acharya," "Pandit," "Drishta," and "Guru," making it amply explicit that the teacher is that revered person who dispels the darkness of his disciples and leads their path to the ultimate destination of Ultimate Reality which is One, Unique, Absolute... timeless and space-less. Add the clinical teaching at bedside and pre-op, per-op, and post-op teaching to this unsolved conundrum and the task of assessing a great surgical teacher is still a long journey to reach the destination. Though the science of teaching and the art of teaching are by illusion miscalculated ways apart, but like a dedicated disciple takes a dip inside, both the science of teaching and the art of teaching mingle into the same stream of the ocean of consciousness. 
An elegant aphorism for great surgical teachers is elucidated as follows:

"That the great surgical teachers shine like stars in the rolling pitch-darkness of night, instead of limiting the challenges they come across; they by their dexterity, deftness and featliness challenge their limits and transcend all the formalistic barriers and enrich the posterity with innovative ideas and styles."

\section{References}

1. Dickinson KJ, Bass BL, Pei KY (2020) The current evidence for defining and assessing effectiveness of surgical educators: a systematic review. World J Surg 44(10):3214-3223. https://doi.org/10. 1007/s00268-020-05617-9

2. Dean B, Jones L, Garfjeld Roberts P, Rees J (2017) What is known about the attributes of a successful surgical trainer? A Systematic Review. J Surg Educ 74(5):843-850. https://doi.org/10.1016/j. jsurg.2017.01.010

3. Sutton PA, Beamish AJ, Rashid S, Elsey E, Mohan HM, O'Regan D (2018) Attributes of excellent surgical trainers: an analysis of outstanding trainers. Int J Surg 52:371-375. https://doi.org/10. 1016/j.ijsu.2017.10.007

4. Swendiman RA, Hoffman DI, Bruce AN, Blinman TA, Nance ML, Chou CM (2019) Qualities and methods of highly effective surgical educators: a grounded theory model. J Surg Educ 76(5):12931302. https://doi.org/10.1016/j.jsurg.2019.02.011

5. Srinivasan M, Li ST, Meyers FJ et al (2011) "Teaching as a competency": competencies for medical educators. Acad Med 86(10): 1211-1220. https://doi.org/10.1097/ACM.0b013e31822c5b9a

6. Ker JS, Williams B, Reid M, Dunkley P, Steele RJ (2003) Attributes of trainers for postgraduate training in general surgerya national consensus. Surgeon. 1(4):215-220. https://doi.org/10. 1016/s1479-666x(03)80020-3

7. Dickinson KJ, Bass BL, Pei KY (2020) What embodies an effective surgical educator? A grounded theory analysis of resident opinion [published online ahead of print, 2020 Jul 1]. Surgery:S00396060(20)30270-1. https://doi.org/10.1016/j.surg.2020.04.056

8. Gibson SJ, Porter J, Anderson A, Bryce A, Dart J, Kellow N, Meiklejohn S, Volders E, Young A, Palermo C (2019) Clinical educators' skills and qualities in allied health: a systematic review. Med Educ 53(5):432-442. https://doi.org/10.1111/medu.13782

9. Menachery EP, Wright SM, Howell EE, Knight AM (2008) Physician-teacher characteristics associated with learner-centered teaching skills. Med Teach 30(5):e137-e144. https://doi.org/10. $1080 / 01421590801942094$

10. Ramani S (2008) Twelve tips for excellent physical examination teaching. Med Teach 30(9-10):851-856. https://doi.org/10.1080/ 01421590802206747

11. Kim RH, Mellinger JD (2020) Educational strategies to foster bedside teaching. Surgery. 167(3):532-534. https://doi.org/10.1016/j. surg.2019.06.007

12. Sutkin G, Wagner E, Harris I, Schiffer R (2008) What makes a good clinical teacher in medicine? A review of the literature. Acad Med 83(5):452-466. https://doi.org/10.1097/ACM.0b013e31816bee61

13. Chen XP, Williams RG, Smink DS (2015) Dissecting attending surgeons' operating room guidance: factors that affect guidance decision making. J Surg Educ 72(6):e137-e144. https://doi.org/ 10.1016/j.jsurg.2015.06.003
14. Pernar LI, Ashley SW, Smink DS, Zinner MJ, Peyre SE (2012) Master surgeons' operative teaching philosophies: a qualitative analysis of parallels to learning theory. J Surg Educ 69(4):493498. https://doi.org/10.1016/j.jsurg.2012.02.002

15. Iwaszkiewicz M, Darosa DA, Risucci DA (2008) Efforts to enhance operating room teaching. J Surg Educ 65(6):436-440. https://doi.org/10.1016/j.jsurg.2008.07.006

16. Kieu V, Stroud L, Huang P et al (2015) The operating theatre as classroom: a qualitative study of learning and teaching surgical competencies. Educ Health (Abingdon) 28(1):22-28. https://doi. org/10.4103/1357-6283.161845

17. Sampene KC, Littleton EB, Kanter SL, Sutkin G (2019) Preventing error in the operating room: five teaching strategies for high-stakes learning. J Surg Res 236:12-21. https://doi.org/10.1016/j.jss.2018. 10.050

18. Sutkin G, Littleton EB, Kanter SL (2015) How surgical mentors teach: a classification of in vivo teaching behaviors part 1: verbal teaching guidance. J Surg Educ 72(2):243-250. https://doi.org/10. 1016/j.jsurg.2014.10.003

19. Sutkin G, Littleton EB, Kanter SL (2015) How surgical mentors teach: a classification of in vivo teaching behaviors part 2: physical teaching guidance. J Surg Educ 72(2):251-257. https://doi.org/10. 1016/j.jsurg.2014.10.004

20. Roberts NK, Brenner MJ, Williams RG, Kim MJ, Dunnington GL (2012) Capturing the teachable moment: a grounded theory study of verbal teaching interactions in the operating room. Surgery. 151(5): 643-650. https://doi.org/10.1016/j.surg.2011.12.011

21. Sutkin G, Littleton EB, Kanter SL (2018) Intelligent cooperation: a framework of pedagogic practice in the operating room. Am J Surg 215(4):535-541. https://doi.org/10.1016/j.amjsurg.2017.06.034

22. Timberlake MD, Mayo HG, Scott L, Weis J, Gardner AK (2017) What do we know about intraoperative teaching?: a systematic review. Ann Surg 266(2):251-259. https://doi.org/10.1097/SLA. 0000000000002131

23. Rose JS, Waibel BH, Schenarts PJ (2011) Disparity between resident and faculty surgeons' perceptions of preoperative preparation, intraoperative teaching, and postoperative feedback. J Surg Educ 68(6):459-464. https://doi.org/10.1016/j.jsurg.2011.04.003

24. Pugh CM, DaRosa DA, Glenn D, Bell RH Jr (2007) A comparison of faculty and resident perception of resident learning needs in the operating room. J Surg Educ 64(5):250-255. https://doi.org/10. 1016/j.jsurg.2007.07.007

25. Vollmer CM Jr, Newman LR, Huang G, Irish J, Hurst J, Horvath K (2011) Perspectives on intraoperative teaching: divergence and convergence between learner and teacher. J Surg Educ 68(6):485-494. https://doi.org/10.1016/j.jsurg.2011.05.010

26. Nisar PJ, Scott HJ (2011) Key attributes of a modern surgical trainer: perspectives from consultants and trainees in the United Kingdom. J Surg Educ 68(3):202-208. https://doi.org/10.1016/j. jsurg.2010.12.010

27. McKendy KM, Watanabe Y, Lee L et al (2017) Perioperative feedback in surgical training: a systematic review. Am J Surg 214(1): 117-126. https://doi.org/10.1016/j.amjsurg.2016.12.014

28. Snyder RA, Tarpley MJ, Tarpley JL, Davidson M, Brophy C, Dattilo JB (2012) Teaching in the operating room: results of a national survey. J Surg Educ 69(5):643-649. https://doi.org/10. 1016/j.jsurg.2012.06.007

29. Trehan A, Barnett-Vanes A, Carty MJ, McCulloch P, Maruthappu $M$ (2015) The impact of feedback of intraoperative technical performance in surgery: a systematic review. BMJ Open 5(6):e006759. Published 2015 Jun 15. https://doi.org/10.1136/bmjopen-2014006759

30. Singh P, Aggarwal R, Zevin B, Grantcharov T, Darzi A (2014) A global Delphi consensus study on defining and measuring quality in surgical training. J Am Coll Surg 219(3):346-53.e7. https://doi.org/ 10.1016/j.jamcollsurg.2014.03.051 
31. Cox SS, Swanson MS (2002) Identification of teaching excellence in operating room and clinic settings. Am J Surg 183(3):251-255. https://doi.org/10.1016/s0002-9610(02)00787-0

32. Boerebach BC, Arah OA, Busch OR, Lombarts KM (2012) Reliable and valid tools for measuring surgeons' teaching performance: residents' vs. self-evaluation. J Surg Educ 69(4):511-520. https://doi.org/10.1016/j.jsurg.2012.04.003

33. Gardner AK, Timberlake MD, Dunkin BJ (2019) Faculty development for the operating room: an examination of the effectiveness of an intraoperative teaching course for surgeons. Ann Surg 269(1): 184-190. https://doi.org/10.1097/SLA.0000000000002468

34. Mahoney A, Crowe PJ, Harris P (2010) Exploring Australasian surgical trainees' satisfaction with operating theatre learning using the 'surgical theatre educational environment measure. ANZ J Surg 80(12):884-889. https://doi.org/10.1111/j.1445-2197.2010.05430. $\mathrm{x}$

35. Beckman TJ, Ghosh AK, Cook DA, Erwin PJ, Mandrekar JN (2004) How reliable are assessments of clinical teaching? A review of the published instruments. J Gen Intern Med 19(9):971-977. https://doi.org/10.1111/j.1525-1497.2004.40066.x

36. Arah OA, Heineman MJ, Lombarts KM (2012) Factors influencing residents' evaluations of clinical faculty member teaching qualities and role model status. Med Educ 46(4):381-389. https://doi.org/10. 1111/j.1365-2923.2011.04176.x

37. Anderson CI, Gupta RN, Larson JR, Abubars OI, Kwiecien AJ, Lake AD, Hozain AE, Tanious A, O'Brien T, Basson MD (2013) Impact of objectively assessing surgeons' teaching on effective perioperative instructional behaviors. JAMA Surg 148(10):915-922. https://doi.org/10.1001/jamasurg.2013.2144
38. Woods NN (2011) Evaluation matters: lessons learned on the evaluation of surgical teaching. Surgeon 9(Suppl 1):S43-S44. https:// doi.org/10.1016/j.surge.2010.11.016

39. Hartford W, Nimmon L, Stenfors T (2017) Frontline learning of medical teaching: "you pick up as you go through work and practice". BMC Med Educ 17(1):171. Published 2017 Sep 19. https:// doi.org/10.1186/s12909-017-1011-3

40. Muller JH, Irby DM (2006) Developing educational leaders: the teaching scholars program at the University of California, San Francisco, School of Medicine. Acad Med 81(11):959-964. https://doi.org/10.1097/01.ACM.0000242588.35354.db

41. Wilkerson L, Irby DM (1998) Strategies for improving teaching practices: a comprehensive approach to faculty development. Acad Med 73(4):387-396. https://doi.org/10.1097/00001888199804000-00011

42. Collins J (2005) The needs of an educator. J Am Coll Radiol 2(11): 914-918. https://doi.org/10.1016/j.jacr.2005.02.010

43. Steinert Y, Mann K, Anderson B, Barnett BM, Centeno A, Naismith L, Prideaux D, Spencer J, Tullo E, Viggiano T, Ward H, Dolmans D (2016) A systematic review of faculty development initiatives designed to enhance teaching effectiveness: a 10-year update: BEME guide no. 40. Med Teach 38(8):769-786. https:// doi.org/10.1080/0142159X.2016.1181851

44. Kumar S (2019) Evidence in surgery - levels and significance. Ind J Surg 81(4):307-316

Publisher's Note Springer Nature remains neutral with regard to jurisdictional claims in published maps and institutional affiliations. 